\title{
máscaras envelhecidas das travestis nos espaços urbanos
}

\author{
RODRIGO PEDRO CASTELEIRA ${ }^{81}$
}

\begin{abstract}
RESUMO
O presente trabalho tem por objetivo investigar a identidade do envelhecimento a partir das memórias das travestis com idade acima de 40 (quarenta) anos da cidade de Maringá, no Paraná, baseando-se nos estudos da oralidade de suas memórias, bem como a compreensão que as travestis possuem da velhice em relação ao próprio corpo, a visibilidade de ser travesti e como a transformação de seus corpos lhes dá suporte, ou não, para uma resistência à velhice. Pretende, ainda, revelar como se dá a relação do corpo enquanto transformação constante, quais implicações os processos de modificação exerceram, quais as preocupações com o envelhecimento e se o cruzamento entre ser travesti e envelhecimento Ihes transportam para uma possível invisibilidade social.
\end{abstract}

Palavras-chave: Travesti, Envelhecimento, Cidade.

A proposta de artigo será a de discutir a manifestação de gênero, especificamente o masculino que se traveste de feminino, chamada travesti, nos espaços urbanos, tendo como referências as definições de gênero pautadas por Judith Butler (2003) entremeadas às discussões das travestis como sujeitos sociais sob a ótica de outsiders, conforme as definições de Howard S. Becker (2008), além de se pautar nas análises dos processos de envelhecimento das travestis e suas relações com o corpo. Corpo este que rompe com o esperado arcabouço biológico, que se reinterpreta no gênero sem, no entanto, se desvencilhar dos processos do envelhecimento e das necessidades de trânsito nos espaços urbanos.

Aqui, o ser travesti não implica necessariamente em ser profissional do sexo, o que ocorre comumente no senso comum. No presente trabalho o que se pretende é estabelecer uma relação entre envelhecimento, travesti e espaços urbanos, mas tendo em mente que a palavra travesti será associada ao artigo feminino durante o

${ }^{81}$ Mestrando em Ciências Sociais pela Universidade Estadual de Maringá (UEM), Paraná. 
desenvolvimento do texto, uma vez que ela representa a feminilidade, o ser feminino e feminina.

Ainda que em espaços não urbanos, Gilberto Freyre, em Sobrados e Mucambos (1977), revela que outrora as manifestações de travestilidade apenas se davam em momentos específicos no Brasil do século XIX, porém, já figurando como uma forma de romper com os sistemas binários do gênero. Os 'efeminados' observados por Freyre, aqui pretensamente utilizados como sinônimos de (ser) travesti, tem a possibilidade de se travestirem como mulheres nos carnavais de teatro do século XIX em meio a "uma sociedade patriarcal brasileira, cheia de repressões, abafos, opressões” (FREYRE, 1977, p. 111) já como uma postura desviante, o que Becker consideraria como outsider (Cf. BECKER, 2008).

Ao traçar a travesti e o envelhecimento, não como prerrogativa para uma análise detida do que é a travesti e da velhice, o artigo pretende suscitar um outro olhar tanto para elas como para esse processo, que não pode também ser entendido meramente como biológico ou cronológico.

\section{ONTOLOGIA ${ }^{82}$ TRAVESTI COMO SINÔNIMO DE OUTSIDERS?}

A identidade de uma pessoa não se manifesta de forma unívoca, universal, constante, mas depende de uma soma de aspectos intrínsecos e extrínsecos de cada pessoa, onde a noção de gênero se mescla à própria identidade. A identidade é suscitada a partir das relações com o outro, os que são em oposição aos que não são, os de dentro e os de fora, as identidades socialmente aceitas e os 'desvios'. A travesti figura como um ser que se encerra fora das identidades heteronormativas, que rompe com a linearidade, com uma pretensa continuidade de gênero ou de expressão sexual, vista como algo de fora, descontínuo da norma e da normalidade. Conforme Pedro Paulo Sammarco Antunes (2011, p.37-38) o "normal está associado ao correto e anormal ao incorreto, o que também ocorre com o que se define por sexualidade humana. Ela varia conforme a época e o local em questão. Atualmente, ou há homens ou mulheres. Travestis não se encaixam

${ }^{82}$ Aqui ontologia se refere especificamente àquela do campo filosófico, sobre o estudo do Ser. 
na definição daquilo que é considerado homem, nem naquilo que é considerado mulher". Butler descreve as relações de norma e descontinuidades de gênero ao afirmar que:

Os espectros de descontinuidade e incoerência, eles próprios só concebíveis em
relação a normas existentes de continuidade e coerência, são constantemente
proibidos e produzidos pelas próprias leis que buscam estabelecer linhas causais
ou expressivas de ligação entre o sexo biológico, o gênero culturalmente
constituído e a "expressão" ou "efeito" de ambos na manifestação do desejo
sexual por meio da prática sexual. (...) A matriz cultural por intermédio da qual a
identidade de gênero se torna inteligível exige que certos tipos de "identidade" não
possam "existir" - isto é, aquelas em que o gênero não decorre do sexo e aquelas
em que as práticas do desejo não "decorrem" nem do "sexo" nem do "gênero".
(BUTLER, p. 38-39)

Essas identidades que rompem com a matriz que pressupõe regularidade e 'norma' do gênero e das manifestações de sexo podem ser explicadas sob a ótica do desvio, uma vez que a ação dos desviantes não implica na quebra da norma, "mas uma consequência da aplicação por outros de regras e sanções a um "infrator". O desviante é alguém a quem esse rótulo foi aplicado com sucesso; o comportamento desviante é aquele que as pessoas rotulam como tal” (BECKER, 2008, p. 22). O gênero, ao quebrar a norma, pode ser observado como um desvio (outsider), não pelos próprios desviantes, mas pelos outros, como "uma consequência das reações dos outros ao ato de uma pessoa (...) se um ato é ou não desviante, portanto, depende de como outras pessoas reagem a ele" (Id., passim, 22-24). Becker usa outsider especificamente para

designar aquelas pessoas que são consideradas desviantes por outras, situandose por isso fora do círculo dos membros "normais" do grupo. Mas o termo contém um segundo significado, cuja análise leva a um outro importante conjunto de problemas sociais: "outsiders", do ponto de vista da pessoa rotulada de desviante, podem ser aquelas que fazem as regras de cuja violação ela foi considerada culpada. (Id., p. 27)

Os outsiders não se consideram outsiders, uma vez que congregam regras sociais criadas por grupos específicos, como travestis que partilham de elementos identitários comuns entre si, porém, socialmente observadas pelos não travestis como seres à margem do círculo da dita normalidade. Não se trata de um comportamento (travesti) estanque, ou observável a priori, o mesmo não se categoriza "no próprio comportamento, mas na interação entre a pessoa que comete um ato e aquelas que reagem a ele" (Id.).

A travesti instaura um outro corpo distinto do masculino biológico: hormonização, silicone, roupas, saltos, perucas, maquiagem, o que se choca com os demais corpos revelando-se como um corpo outsider, que rompe com a genitália biológica e as ações 
esperadas a partir dela. Esse mesmo corpo outsider, não como ser, ontologicamente falando, mas delimitada sob a forma de fronteira que varia conforme a política reguladora tem toda sua extensão permeável, o que implica num corpo como produto de uma performance, de um estilo corporal, não como acaso, e sim dotado de intencionalidade, segundo uma "construção dramática e contingente de sentido" (BUTLER, p. 199). Desta forma, a genitália biológica não se resume a um ato restrito, e sim ato permeável, político, fluídico, revelando a postura de que os gêneros não são verdadeiros ou falsos, falaciosos ou reais, uma vez que sejam constructos sociais performativos, porém, detém em si um caráter de algo incrível, dadas suas estratégias de rompimento com 0 binarismo essencialista de "masculinidade e feminilidade verdadeiras ou permanentes" (BUTLER, $p$. 201).

Se, como defende Butler, o gênero não carrega essa característica ontológica, automaticamente o conceito de ontologia travesti se esvai, uma vez que a travestilidade se encerra no âmbito performático do gênero, contudo, não destitui a definição de outsider dada a ela. Parece aporético tratar a travesti como ser e destituir uma ontologia travesti, contudo, a performance, as estratégias, o rompimento, desestabilizam as pilastras que fundamentam e cristalizam uma ontologia, uma vez que as estratégias se pautam nos rompimentos.

Tais rompimentos das normas sociais não possuem uma data específica no Brasil, contudo, pode-se vislumbrar quando e como citadas as quebras das regras de gênero, corpos outsiders, travestis e suas movimentações. Gilberto Freyre ao inventariar o gênero, e outras situações, no Brasil Colônia revela mulheres que rompiam com a feminilidade, chefiando a casa tal como homem, porém, o mais emblemático, e menos esmiuçado, é acerca dos homens efeminados. O autor não descreve detidamente esses homens efeminados, porém, dá indícios para se pensar a travestilidade em espaços e tempo determinado, como o carnaval de teatro, oposto ao carnaval considerado fino, elegante, enredado no "mais completo silêncio" (FREYRE, p. 111), em meados dos 1840. Apesar de antagônicos, um não exclui o outro, como descreve Freyre:

É certo que esse carnaval elegante, fino, silencioso, de fantasias de seda, não matou o outro: o grosseiro, plebeu, ruidoso, com oportunidades para os moços expandirem sua mocidade, para os negros exprimirem sua africanidade (de certo modo recalcada nos dias comuns), para pretos, escravos, moças, meninos gritarem, dançarem e pularem como se não fossem de raça, de classe, de sexo e de idade oprimidas pelos senhores dos sobrados. (Id.) 
O carnaval de teatro permitia o rompimento dos paradigmas das normas da época, uma possibilidade de movimentos outsiders, onde as máscaras, consideradas sagradas, escamoteavam quem rompia com tais paradigmas, como os indivíduos dotados de certa travestilidade, pois figurava como "a oportunidade a efeminados para se trajarem de modo semelhante ao das mulheres. A oportunidade a mulheres meio masculinas para se trajarem de modo semelhante ao dos homens" (Id.). Os efeminados se movimentavam na sociedade brasileira transitória do rural ao urbano, como Sobrados e Mucambos descreve de forma breve, contudo, não existem elementos que indiquem com efetividade essas mobilidades, como eram tais efeminados, quais elementos comportamentais dispunham, quais referenciais para a feminilidade. Apesar de poucos elementos, não destitui uma análise desse recorte sob uma ótica de possibilidade de inventariado inicial brasileiro da travestilidade num espaço intermediário entre rural e urbano, além de inferir a possibilidade de que: tais efeminados sejam sinônimos de travesti, que a identidade travesti foge dos conceitos 'normativos' de gênero e que a travestilidade, ao romper com tais normas, suscita a postura de outsider.

O que fica patente é inexistência de uma ontologia travesti conforme os moldes de Butler, elas existem, mas não há uma existência a priori metafísica universalizante, o que empiricamente vai ao encontro com a observação de Freyre dos anos de 1800 no Brasil, que não data ou tenta elaborar um conceito a priori do que seja esse padrão de efeminado, seu surgimento, o que corrobora para a mesma desmistificação do gene travesti, o que implica em negação da questão do enunciado supracitado (Ontologia travesti como sinônimo de outsiders?), sem rejeitar a afirmação do ser travesti como outsider a partir dos processos de modificação corporal e escolhas intencionais pautadas em uma construção dotada de dramaticidade e contingência.

O conceito de outsider não se resume, como já descrito, apenas às travestis, mas a todo aquele que fora considerado como fora de um padrão ou norma, da mesma maneira que uma pessoa envelhecida em oposição a uma jovem. Faz-se necessário esmiuçar, ainda que teoricamente, os recortes acerca do envelhecimento e cruzar as relações entre travestilidade e envelhecimento, não para postular uma invisibilidade óbvia, mas sim como pressuposto para pensar os espaços das cidades como cenário de mobilidades, inacessibilidade, presença e identidades. Ao que parece, velhos, travestis, homossexuais, 
são tidos como outsiders, como desviantes por não serem jovens, reelaborarem o corpo ou pela homossexualidade. As cidades enquanto espaço do diverso pode ser pensadas sob a ótica desses sujeitos, em como eles mesmos se observam, em quais 'regras e normas' se consideram participantes.

\section{MOVIMENTAÇÕES INVISÍVEIS DE TRAVESTIS NO ENVELHECIMENTO}

Os espaços eleitos para as movimentações das travestis, e desta análise, são as cidades que, como afirma Simmel (1976, p.21), "são sede da mais alta divisão econômica do trabalho", onde fenômenos extremos ocorrem bem como a oferta crescente de mais trabalho e mais divisões do mesmo. As pessoas encerradas nas cidades precisam superar a dificuldade de firmar sua própria identidade e personalidade, onde

o aumento quantitativo em importância e dispêndio de energia atingem seus limites, a pessoa se volta para as diferenças qualitativas, de modo a atrair, por alguma forma, a atenção do círculo social, explorando sua sensibilidade e diferenças. Finalmente, o homem é tentado a adotar as peculiaridades mais tendenciosas, isto é, as extravagâncias especificamente metropolitanas do maneirismo, capricho e preciosismo. Agora, o significado dessas extravagâncias não jaz absolutamente no conteúdo de tal comportamento, mas antes na sua forma de "ser diferente", de sobressair de forma notável e assim atrair a atenção (ld., p. 22)

A travesti assimila essa postura que Simmel observa: maneirismos, extravagâncias e utilização de energia para que sejam notadas suas subjetividades que são arrancadas e transformadas em vidas objetivas. Há, então, uma redução do indivíduo à objetividade, por isso, de sua intencionalidade em dispor de sua energia para salvaguardar sua subjetividade. As cidades, então, fornecem as arenas para as disputas travadas em si mesmo e para com os demais, entre as travestis e não travestis, entre os jovens e velhos, homens e mulheres, mas não apenas nas relações dicotômicas, pois pode haver disputas entre os próprios pares. No tocante aos processos peculiares para as travestis velhas, faz-se necessário compreender como se dá o envelhecimento num palco que tenta sufocar a subjetividade.

O envelhecimento não é uma etapa que se chega de imediato, mas um processo que se inicia com o nascimento, ou seja, o envelhecimento é um processo indissociável ao ser humano e revela conquistas que são feitas socialmente, gradativas e delimitadas por fronteiras da idade, como descreve Barros (1999, p. 47): 
As idades são apreendidas como etapas que definem estilos que podem ou não ser adotados e delimitam fronteiras entre indivíduos e segmentos sociais, como podemos ver na interpretação da juventude ou da "terceira idade" como um modo de ser e de estar no mundo. A juventude, por um lado, apresenta-se como um contraste à velhice e como um padrão de vida que deve ser estendido a todas as faixas etárias. A velhice estigmatizada, por outro lado, não desaparece de nossa realidade. Ela é apenas colocada em outro lugar e adiada para outro tempo de vida de cada um de nós.

O processo de envelhecimento retira a visibilidade das pessoas, de seus desejos, e Ihes imprime a proximidade da morte, que ao máximo se tenta desvencilhar, figurando a cidade como palco desses processos. Simmel (1976) chama esse palco de lugar de impessoalidade e de promoção da subjetividade, como tentativa de se sobressair "de forma mais notável e assim atrair atenção" (SIMMEL, 1976, p. 22), o que revela uma tentativa do indivíduo de sobreviver ao sufocamento da cidade, de permanecer cognoscível para os demais, por isso apela às extravagâncias, e, sobretudo para si mesmo. A cidade é o espaço para se observar como as travestis envelhecidas e envelhecendo agem, mas acima de tudo, suas visões do espaço urbano que elegem aspectos sociais específicos. A importância da cidade se faz sentir nas "lembranças não como entidade em abstrato, mas como experiência de vida" (BARROS, p.45). Enquanto as pessoas envelhecem, os espaços urbanos à sua volta são modificados, mas não a eles adaptados, e o sufocamento delimitado por Simmel parece apenas superável quando podem retratar o que viveram a partir de suas memórias, "a expressão "no meu tempo" que ouvimos de velhos e velhas para se referir ao passado, comparando-o com o presente, traz de forma clara e contundente uma das maneiras que concebem os limites impostos pelas mudanças urbanas que não facilitam sua mobilidade" (Id., p. 55), tem-se, assim, 'pistas' das interações sociais e de seus contextos relacionais que vinculam $o$ espaço do corpo e dos espaços urbanos. Sem a dimensão do espaço seria praticamente impossível recordar, contudo, ainda que lembrada sob diversas dimensões, é delimitado de forma "básica pelo olhar" (Cf. BARROS, p. 48). Se hoje as travestis se valem das próteses de silicone, 'no tempo' das mais velhas as práticas eram a de hormonização e da injeção de silicone industrial, as posturas de mobilidades eram outras, bem como a relação com o próprio corpo.

O corpo 'construído' pela travesti é um corpo que deve atender seus propósitos subjetivos e privados, enquanto desejo de ser mais feminina, ter cabelos mais compridos, 
entre outros, mas atende também propósitos objetivos e públicos, uma vez que seu corpo se expõe aos demais corpos. Baudrillard (2008, p. 168-178) revela um corpo não apenas como sinônimo de organismo, mas como consumo, e neste aspecto é possível associar ao que escreve ao corpo da travesti, uma vez que a beleza impositiva leva ao erótico, ao sexual. Porém, o corpo 'transformado' ou 'tecnológico' está sujeito às ações do tempo, então, a busca pela eterna beleza esbarra no envelhecimento, na redução gradativa da autoestima.

Existe uma negatividade que envolve o processo do envelhecer, consituindo-se como processo degenerativo, de definhamento, transfigura-se como incapaz, impotente, não produtivo, antes o contrário, um ser dependente (FÁVERO, 2010). No entanto, a potencialidade humana lhe permite experimentar o desenvolvimento através das várias fases desse processo, que vai da concepção até a morte física. Assim, cada travesti, por exemplo, tem a oportunidade de construir o próprio corpo e a sua história considerando o tempo e a especificidade individual, desfrutando suas habilidades e as fases da vida que vive que promoverá o desempenho próprio desta ou da próxima fase.

Fávero (2010) defende a ideia de que se envelhece mais pela cultura do que pelo próprio corpo, em suas palavras, "a cultura dominante media significados sobre o envelhecimento e isso repercute nas nossas vidas desde muito cedo, o que nos leva à preocupação com os chamados sinais de envelhecimento nos nossos corpos" (FÁVERO, 2010, p. 244). A travesti envelhece segundo estes conceitos de fase de vida e de cultura, ainda que seu corpo esteja submetido à busca constante da beleza e da recusa do tempo, elas têm a possibilidade e oportunidade de envelhecer vivenciando, em certos casos, as doenças comuns do envelhecimento, as que também são ocasionadas pelo uso excessivo de hormônios femininos e outras deixadas pela utilização do silicone industrial utilizados para 'construir' o corpo.

Mas esta categoria de corpo imprime não a ideia de que as pessoas sejam avaliadas pelo quanto sejam idosas, mas pelo quanto não são jovens, isso graças à dicotômica categoria de cultura: ser jovem e ser idoso, como esclarece Fávero, ao descrever que "esses dois aspectos tem razão de ser no contexto da sociedade de consumo, no qual o corpo torna-se um projeto a ser trabalhado, moldado e controlado, um lugar de autoidentidade e, ao mesmo tempo, de consumo, um objeto, enfim, como discutido antes" (Id., 2010, p. 245). 
Mesmo como objeto é possível retardar o processo de envelhecimento com o uso de cosméticos, medicamentos, procedimentos cirúrgicos, entre outros, suscitando a questão sobre a existência de fato de um período da vida para que se considere uma pessoa como velha, "assim, tecnologias cada vez mais sofisticadas para o monitoramento desse corpo são criadas continuamente, em um mundo de espelhos, tanto no sentido literal como não literal, que revela esse corpo por inteiro e em detalhes, ao mesmo tempo em que a mídia expõe corpos seminus dentro de um padrão de perfeição que nega a idade e que defende uma magreza ideal (...)" (Id.). Mas será que esse mesmo corpo não poderia, ainda que invisível, ser livre? As lembranças rememoradas sugerem apenas o fracasso como meta alcançada, quando apenas são uma releitura da velhice, como delimita Barros (p. 57), no entanto, como a própria autora descreve,

outras formas de se perceber no mundo são criadas, refazendo-se concepções sobre si mesmas e sobre as relações sociais. O corpo velho pode deixar de carregar o peso negativo da mulher [ou da travesti] que não é mais capaz de procriar e que não é mais atraente para ser, agora, o corpo liberto do controle social. Um corpo plástico sobre o qual se pode ter algum controle, definir padrões de sexualidade e erotismo e forma de cuidados médicos e estéticos. (grifo nosso)

Há uma nova postura diante do corpo envelhecido, invisível socialmente. Ainda que a autora discorra sobre o corpo da mulher, a inferência ao corpo da travesti pode ser pensada, já que representa e se apresenta feminina. As travestis envelhecidas já podem se 'dar ao luxo' de sentirem-se livres de diversas expectativas negativas do próprio corpo: beleza eterna, agilidade, todavia, o mesmo corpo imprime sentimentos de insatisfação física, já que não poderão mais "concorrer nos jogos de sedução e de conquistas amorosas", sendo constrangido por condutas sociais "interiorizadas pelos seus portadores" (BARROS, 46-55, passim).

\section{CONFRONTOS: RELAÇÕES DE SI MESMA.}

Como a pesquisa está em processo, as análises das memórias orais foram postergadas, partido-se primeiramente para a pesquisa de obras e de sujeitos que estejam na faixa etária de corte, o que por si gera um certa dificuldade, tanto pelas travestis que se disponham a participar, ou ainda pelas considerações subjetivas das próprias idades. Como sugere Barros (2006, p. 47): 
A flexibilização das classificações das idades, o esmaecimento das fronteiras etárias, a pluralidade e a heterogeneidade de experiências geracionais têm sido apontados como fenômenos característicos da sociedade modernocontemporânea. Nesse contexto sociocultural, as idades são apreendidas como etapas que definem estilos que podem ou não ser adotados e delimita fronteiras entre indivíduos e segmentos sociais, como podemos ver na interpretação da juventude ou da "terceira idade" como um modo de ser e de estar no mundo.

As observações, conversas ainda informais e a análise de dissertações ${ }^{83}$ a respeito de uma travesti ${ }^{84}$ de 49 anos, nascida em Maringá e participante de uma religião de matriz africana, na condição de Mãe de Santo de uma casa de Umbanda na mesma cidade, revelam a forma que lida com o corpo e sua percepção de si no processo do envelhecimento. Essa travesti não possui vinculação com o ser profissional do sexo, mas desempenha outra atividade como já citado, Mãe de Santo, e todas as relações de trabalho que esta atividade implica. Os processos de (re)construção corporal aos 32 anos de idade moldados pelo silicone industrial revelam uma prática comum entre diversas travestis, considerado por muitas como beleza e dor como sinônimos, implicando em uma visão de si mais feminina por suas curvas, seus quadris mais avolumados, seus seios mais fartos. Com o decorrer do tempo seria possível questionar que as demais pessoas não percebem as travestis velhas? A velhice confere mais sutileza no trato cotidiano extra-lar? Ao analisar uma de suas falas Emanuela ${ }^{85}$ descreve que:

${ }^{83}$ Confira, por exemplo, a dissertação de mestrado de Joyce. M. Shimura, onde a mesma parte de uma análise de memórias travestis vinculadas à educação, corpo e sexualidade.

${ }^{84}$ Tive um primeiro contato com ela em 2003, quando fui conhecer a casa por causa de uma festa de Cosme e Damião, muito conhecida tanto na periferia como no centro da cidade. Ainda que não pensasse em estudar a travestilidade, fascinou-me observar cada gesto dela como Mãe de Santo, que naquele momento estava incorporada, conhecendo a pessoas apenas horas depois. Retornei diversas vezes para sua Casa, mas com o olhar mais voltado à pesquisa, medindo, calculando, e percebendo que qualquer mensuração técnica apenas implicaria em avaliações estéreis. Ao ingressar no mestrado a oportunidade de observar com mais seriedade e deixar que o sujeito fale de si revelou a possibilidade de um estudo mais conciso, acadêmico e humano.

${ }^{85} \mathrm{O}$ nome Emanuela é sugestão da própria autora da dissertação, como garantia ética de salvaguardar sua identidade. Como partirei também da mesma pessoa como parte da dissertação, penso que analisar suas ações empíricas e falas já delimitadas figure como um processo preliminar para a confecção de uma escrita não mais ampla, mas sob outro viés, sem que seja necessário retomar as mesmas questões já realizadas, o que poderia frustrar a pesquisada, contudo, as questões podem ser retomadas de forma ou análise diferente, como elucida Becker "Nada permanece igual. Nada é igual a coisa alguma. Não operamos no mundo dos químicos, onde podemos tirar uma amostra de substância pura da prateleira e saber se ela é a mesma substância que qualquer outro cientista no mundo estará manipulando sob esse nome, ou equivale a ela para todos os efeitos. Nenhuma de nossas substâncias é algo de puro" (2007, p. 122). 


\begin{abstract}
Ah! Hoje na cidade as pessoas me tratam sempre como senhora. Outro dia me perguntaram se eu ia comprar no nome do meu marido, Emanuel. Eu não precisei dizer nada, porque um vendedor mais antigo veio e disse que era eu, o Emanuel era eu! Mas, ela não entendeu e aí eu expliquei: "o Emanuel no caso sou eu, Emanuela". Então, a única coisa que poderia, se eu conseguisse, em termos de mudar, seria os documentos. Mas, aí depois eu paro e penso que eu teria que muda todos os documentos do Centro também e desisto. Dá um pouquinho de constrangimento para a outra pessoa, não para mim (SHIMURA, 2012,p. 72).
\end{abstract}

Os processos de envelhecimento, além de um processo biológico, constituem-se como "construção sociocultural, ligada às expectativas, valores e ética da sociedade" (MEDEIROS, 2005, p. 14), dessa forma, as expectativas de Emanuela enquanto travesti, feminina, envelhecida e envelhecendo, frente à identidade de 'senhora' projetada pelos demais são atendidas? Que elementos outros são necessários para que seja contemplada como sujeito, como feminina, como senhora?

Como 'senhora', estigmatizada pela velhice, pela travestilidade, ela não ignora o passado, uma vez que declara que "Uma vida sem passado é uma vida sem história. Mesmo que você passou por muita dificuldade e foi doloroso, mas hoje se você parar e pensar só serviu de coisas positivas" (Cf. SHIMURA, p. 74), o que corrobora as palavras de Barros sobre as experiências vividas e lembradas, fortemente "valorizada pelos mais velhos como um dos poucos ganhos da velhice, é o fundamento da narrativa da memória e, do ponto de vista de quem lembra, a experiência é uma interpretação de seu passado" (1999, p. 55).

Não importa, aqui, as relações de verdade, tautologia, aporia ou inconstância de suas memórias, o que importa é compreender que suas narrativas, e a partir delas, revelam os planejamentos de suas ações, e que tais lembranças não estão simplesmente prontas e acabadas, e sim reconstruídas a "cada situação e em resposta aos estímulos exteriores" (Idem). O corpo que incorpora, que dança, que se doa, que fora modificado, que sente e se faz sentir, se modifica a cada dia. Sofre as ações do tempo, contudo, agora esse mesmo corpo pode deixar de carregar o peso negativo da atração "para ser, agora, o corpo liberto de controle social. Um corpo plástico sobre o qual se pode ter algum controle, definir padrões de sexualidade e erotismo" (Idem, p. 57). Emanuela, assim, se sente tranquila com o próprio corpo, com suas modificações e os processos de envelhecer, porém, sabe que existem espaços mais tranquilos de trânsito do que outros, como, por exemplo, um Posto de Saúde das proximidades de sua casa, onde não é bem 
vista, nem tratada no feminino, elegendo um mais distante, onde se sente acolhida, respeitada e chamada pelo nome social.

A partir das análises das memórias orais e das relações com o espaço em que tais sujeitos estão, é possível, ainda que de forma superficial, estabelecer questionamentos a fim de orientar a escrita, a compreensão dos processos de envelhecimento, travestilidade, corpo e memória. Perceber como o discurso representa a velhice travesti torna-se importante para pensar as "decisões político-administrativas e do caráter das atividades voltadas para um contato direto com os idosos", como descreve Debert (1999, p. 25) geralmente tomadas pelo gerontólogos, o que não implica que tais decisões acerca do envelhecimento dos sujeitos sejam categorizadas de forma correta e efetiva, uma vez que a velhice é uma construção além da biológica, mas social.

\section{CONSIDERAÇÕES}

A investigação da travestilidade e do envelhecimento, ainda que orientada distante da pesquisa de campo, dá indícios de como tais sujeitos são considerados como fora de dois contextos, o que lhes transporta para a invisibilidade social: o de gênero e o da juventude. A travesti partilha de outros elementos para que seja construída enquanto tal, elaborando outras plasticidades para 0 próprio corpo que contrariam a heteronormatividade, no entanto, a velhice, para além das relações biocronológicas, Ihes chega inevitavelmente como também mais um fator emblemático para suas movimentações pelas cidades. Talvez as travestis não sejam observadas como travestis com o peso dos anos. Talvez seja apenas absorvida como figura feminina velha, e não como travesti. Caso ocorra, a carga do envelhecimento poderia ser uma premissa maior que qualquer outsider de gênero, e questão de gênero se torna secundária, caso sejam realmente coisas distintas, a intersecção entre ambas premissas desemboca num sujeito que precisa, conforme Simmel, de "forma mais notável e assim atrair atenção", numa tentativa de superar o olhar do outro em relação a seus corpos. O envelhecimento, mais que um processo orgânico, está também no âmbito da cultura, onde seria pertinente indagar se a travesti não envelheceria antes, dadas suas alterações corporais.

\section{REFERÊNCIAS}


ANTUNES, Pedro Paulo Sammarco; MERCADANTE, Elisabeth Frohlich. Algumas contribuições da filosofia e sociologia na compreensão do envelhecimento e velhice de travestis. In: Revista Portal de Divulgação, n. 11, Jun. 2011 http://www.portaldoenvelhecimento.org.br/revista/index.php

ANTUNES, Pedro Paulo Sammarco. Longevidade, travestis e a construção do conceito de sexualidade. In: Revista Portal de Divulgação, n. 14, Set. 2011 ehttp://www.portaldoenvelhecimento.org.br/revista/index.php

ANTUNES, Pedro Paulo Sammarco. Travestis envelhecem? Dissertação de Mestrado em Gerontologia. Pontifícia Universidade Católica de São Paulo. São Paulo. 2010.

BARROS, Myriam Moraes Lins de. A velhice na pesquisa socioantropologia brasileira. In: VELHO, Gilberto (org.). Antropologia urbana: cultura e sociedade no Brasil e em Portugal. Rio de Janeiro, Jorge Zahar Ed., 1999, p. 45-64.

BARROS, Myriam Moraes Lins de. Velhos e jovens no Rio de Janeiro: processos de construção da realidade. In: VELHO, Gilberto (org.). Antropologia urbana: cultura e sociedade no Brasil e em Portugal. Rio de Janeiro, Jorge Zahar Ed., 1999, p.156-173.

BAUDRILLARD, Jean. A sociedade de consumo. Lisboa. Edições 70, 2008.

BECKER, Howard S. Segredos e truques da pesquisa. Trad. Maria Luiza X. de A. Borges. Rio de Janeiro, Zahar Ed., 2007.

BECKER, Howard S. Outsiders: estudos de sociologia do desvio. Trad. Maria Luiza X. de A. Borges. Rio de Janeiro, Zahar Ed., 2008.

BENEDETTI, M. R. Toda feita: gênero e identidade no corpo travesti. Anas da II Reunión de Antropologia Del Mercosul, Piriápolis, Nov. 1997.

BENTO, B. A. M. A. A reinvenção do corpo: sexualidade e gênero na experiência transexual (Tese, Departamento de Sociologia / UnB). Brasília, Maio 2003.

BOSI, E. Memória e sociedade: lembranças de velhos. São Paulo: Companhia das Letras, 1994.

BUTLER, Judith. Problemas de gênero: feminismo e subversão da identidade. Taad. Renato Aguiar. Rio de Janeiro, Civilização Brasileira Ed., 2003.

CAMARANO, Ana Amélia (org.). Os novos Idosos Brasileiros: Muito Além dos 60? Rio de Janeiro: IPEA, 2004.

CAMARANO, Ana Amélia (coord.). Como vai o idoso brasileiro? In: Texto para discussão. Rio de Janeiro: IPEA, 1999. 
CASTELLS, Manuel. A questão urbana. Edição revisada, acompanhada de posfácio (1975). Tradução de Arlene Caetano. Coleção Pensamento Crítico - Vol. 48. São Paulo: Paz e Terra, 2000.

DEBERT, Guita Grin. Pressupostos da reflexão antropológica sobre a velhice. In: VELHO, Gilberto (org.). Antropologia urbana: cultura e sociedade no Brasil e em Portugal. Rio de Janeiro, Jorge Zahar Ed., 1999, p. 7-27.

FÁVERO, Maria Helena. Psicologia do gênero: psicobiografia, sociocultura e transformações. Curitiba: Ed. UFPR, 2010.

FREYRE. Gilberto. Sobrados e Mucambos: decadência do patriarcado rural e desenvolvimento do urbano. 5a . Edição. llustrações de Lula Cardoso Ayres; M. Bandeira, Carlos Leão e do autor. Rio de Janeiro. Livraria José Olympio Editora, 1977.

FOUCAULT, M. História da sexualidade I: a vontade de saber. 13a . ed. Rio de Janeiro: Graal, 1999.

1998.

História da sexualidade II: o uso dos prazeres. $8^{a}$. ed. Rio de Janeiro: Graal,

MEDEIROS, Suzana. Brasil: O que dizem os números sobre a pessoa idosa. Trabalho apresentado no XV Encontro Nacional de Estudos Populacionais, ABEP, realizado em Caxambú-MG - Brasil, de 18 a 22 de setembro de 2006.

SHIMURA, Joyce M. ANA, DULCINÉIA E EMANUELA: narrativas travestis e discursos científicos sobre a construção dos corpos na escola. Dissertação de Mestrado Universidade Estadual de Maringá. Programa de Pós-Graduação em Educação para a Ciência e a Matemática. Maringá, 2012.

SILVA, H. Travesti. A invenção do feminino. Rio de Janeiro: Relume-Dumará, 1993.

SIMMEL, Georg. A metrópole e a vida mental. In VELHO, Otávio Guilherme (Org.) 0 fenômeno urbano. Rio de Janeiro: Zahar Editor, 1976, p. 11-25.

SHIMURA, Joyce M. ANA, DULCINÉIA E EMANUELA: narrativas travestis e discursos científicos sobre a construção dos corpos na escola. Dissertação de Mestrado Universidade Estadual de Maringá. Programa de Pós-Graduação em Educação para a Ciência e a Matemática. Maringá, 2012.

SIQUEIRA, Mônica Soares. Sou senhora: um estudo antropológico sobre travestis na velhice. Dissertação de mestrado em Ciências Sociais. Universidade Federal de Santa Catarina. Florianópolis, 2004.

VELHO, Gilberto (org.). Antropologia urbana: cultura e sociedade no Brasil e em Portugal. Rio de Janeiro, Jorge Zahar Ed., 1999. 
WHITE, William Foote. Sociedade de esquina = Street Corner Society: a estrutura social de uma área urbana pobre e degradada. Trad. Maria Lúcia de Oliveira. Rio de Janeiro =: Jorge Zahas Ed., 2005. 